\title{
Pricing Strategy in Multi-Channel Apparel Supply Chain with Showrooming Effect
}

\author{
Shanshan Wang*, Daofang Chang, Tian Luo \\ Institute of Logistics Science and Engineering, Shanghai Maritime University, Shanghai, China \\ Email: *610955177@qq.com
}

How to cite this paper: Wang, S. S. Chang, D. F., \& Luo, T. (2020). Pricing Strategy in Multi-Channel Apparel Supply Chain with Showrooming Effect. American Journal of Industrial and Business Management, 10, 749-774.

https://doi.org/10.4236/ajibm.2020.104051

Received: March 23, 2020

Accepted: April 14, 2020

Published: April 17, 2020

Copyright () 2020 by author(s) and Scientific Research Publishing Inc. This work is licensed under the Creative Commons Attribution International License (CC BY 4.0).

http://creativecommons.org/licenses/by/4.0/

\begin{abstract}
In the apparel supply chain, brick-and-mortar stores rely on sales effort to increase demand. However, the cross channel free-riding behavior of "experience offline, purchase online" will harm sales profit of physical stores. In order to solve the problem, this paper considers a multi-channel apparel supply chain consisting of an upstream manufacturer and a downstream retailer, where the manufacturer opens an online direct channel and the retailer opens offline and online channels. First, a Stackelberg game model is established between the manufacturer and the retailer. Then we study equilibrium retail prices, the sales effort level and the supply chain performance under centralized decision, decentralized decision and surplus profit-sharing (SPS) decision. Finally, the optimal results in the three decisions are compared and analyzed from perspectives of the manufacture, the retailer and the whole supply chain. Our research results show that: 1) surplus profit-sharing contract can improve retailer service level and supply chain profits, which also could avoid price competition among three channels and alleviate the negative impact of showrooming. 2) The greater the showrooming effect in multi-channels, the less the supply chain profits will get. 3) It is beneficial for the retailer to add a retailer's online channel on typical dual channels.
\end{abstract}

\section{Keywords}

Showrooming, Sales Effort, Multi-Channel Apparel Supply Chain, Surplus Profit-Sharing Contract

\section{Introduction}

Clothing industry is the most important and indispensable industry in the world, which has developed very rapidly in the past decades (Guo et al., 2020; Hsiao et al., 2019). Recently, apparel e-commerce has been further developed because of 
the popularity of the Internet, the improvement of online payment security and the convenience of express delivery. However, adding online channels will have a negative impact on sales of the traditional brick-and-mortar store. For example, H \& M opened eight online direct channels in 2017 when compared to 2016, but its store sales fell by $2.3 \%$ despite the number of brick-and-mortar stores increase from 4351 to 4739 . Therefore, in order to reduce the impact of online channel on offline channel, retailers have to provide better offline service. For instance, physical store provides customers with free service of trying on new clothes or shopping guides recommends the suitable clothing style to customers, etc. At this time, the showrooming phenomenon appears, that is, after customers experience the services provided by retailers in physical stores, they turn to online channels to buy clothes at a lower price (Zhang et al., 2017; Viejo-Fernández et al., 2020).

Customer free-riding behavior will decrease the demand and profit of retailers who provide the sales effort (Kato, 2019; Kuksov \& Liao, 2018; Schneider \& Zielke, 2020). Therefore, in order to deal with the problem that a large number of customers turn to online, retailers have to also open online direct channels to divide up a fixed online market, which can increase market coverage, control sales prices and increase profits. For example, Alibaba Cloud in China is promoting a new shopping channel. When the customer experiences the service in the physical store, the shop guides set up the way of adding friends with Wechat to open the retailer's online channel. Then retailers release the clothing's latest styles and related activities in real time through Wechat. However, in the traditional dual-channel supply chain, adding a new channel will aggravate the conflicts among channels, which may affect the profit of each channel. In the face of profit conflicts across multiple channels, some researchers have used centralized models to consider the benefits of the overall supply chain. The centralized model is to determine the decision variables of retailers and manufacturers through one central decision maker, so as to optimize the operational efficiency of the whole supply chain (Li et al., 2019b). However, there are both upstream manufacturers and downstream retailers in the dynamic supply chain, they always ignore individual profits when considering the overall optimal profit. When the whole supply chain is optimal, the manufacturer or retailer may lose profits, which will weaken the enthusiasm of supply chain members. Therefore some researchers have proposed decentralized models that fully consider their own benefits (Fu \& Ma, 2019). The decentralized model can bring maximum profits for individuals, but it will intensify competition between opponents, which is detrimental to the steady development of manufacturers and retailers and has a negative impact on the overall supply chain profits. Therefore, many studies choose a coordination mechanism in order to balance the strengths and weaknesses of centralized and decentralized models. By cooperating with each other, they consider both their own profits and the overall profits, thereby alleviating channel conflicts (Chen et al., 2016). Different problems often adopt dif- 
ferent coordination models. Most of papers about consumer free riding behavior under the dual channel supply chain choose to coordinate from the perspective of controlling service cost (Zhou et al., 2018; Bai et al., 2017).

In the multi-channel supply chain composed of manufacturer online, retailer offline and retailer online, the manufacturer, as the leader of Stackelberg game, sells same clothes to consumers and retailers to earn profits. Meanwhile, retailers set up sales effort to attract customers and expand online direct sales channels to take over online shares. But under this circumstance, how to coordinate profits will be a complex problem. Manufacturers could have brought demand through retailers' sales effort, but the online presence of retailers has had an impact on their demand, so the introduction of a new channel is a challenge to supply chain members. In the past, most of the studies were about the consumer free riding behavior in traditional dual channels (He et al., 2016; Li et al., 2019a; Pu et al., 2017). There are few articles on free riding in multi-channel. Therefore, this paper will study how to reduce the negative impact of free riding behavior of customers in the multi-channel apparel supply chain.

To solve above problems, this article will propose a multi-channel Stackelberg game model in the apparel supply chain. Suppose demands are deterministic, we consider using the SPS coordination mechanism. The retailer's online channel indirectly obtains additional demand through the sales efforts of physical stores, while competing with the manufacturer's online channel. Facing this situation, manufacturers are unwilling to share the retailer's sales effort costs, so they do not adopt the cost sharing contract (CSC) coordination mechanism as commonly used in dual channels. But if customers experience the service in the retail stores, more people choose the manufacturer's online channel, which drives the manufacturer to earn more profits. At this time, manufacturers and retailers can bargain to distribute residual income, so they can sign SPS contracts.

The rest of the article is organized as follows. Section 2 introduces review of related literature. Section 3 describes problem and notation of this paper. Section 4 set up the model and obtains equilibrium solution of the centralized decision, the decentralized decision and the SPS decision. Section 5 studies the influence of two main factors on channel members and supply chain performance by sensitivity analysis. Finally, we make summary and future work in Section 6.

\section{Literature Review}

This paper presents the different performance of the manufacturer and the retailer in three channel models when customers have showrooming behavior in multi-channels, then studies whether profit sharing mechanism can coordinate their price, sale efforts and supply chain profit. Related work mainly includes three aspects: showrooming in multi-channel, sales effort and coordination mechanism.

\subsection{Showrooming in Multi-Channel}

The phenomenon of showrooming is common in of multi-channels apparel 
supply chains, and many researchers have extensive research in this area. Research by Van Baal \& Dach (2005) pointed out that in a dual-channel supply chain consisting of retail's traditional channels and manufacture's electronic direct sales channels, more than $20 \%$ of consumers are free riders. Showrooming will erode the profits of supply chain, which is one of the most important problems faced by companies in different channels. For example, Xing \& Liu (2012) believed that the free-riding effect affects the sales effort of retailers' physical stores, while also restraining the increase in manufacturers' profits and overall supply chain performance. Zhou et al. (2018) studied how showrooming affects pricing between different price model and the same price model, then compares the results with two models in a dual-channel. The results of the study show that under service-cost sharing contracts, showrooming always has a negative impact on retailers' profits. Pu et al. (2017) studied the impact of showrooming on the profits of members in dual channels under certain demand and uncertain demand. This shows that the customer free-riding behavior under dual channels will lead to a decline in online and offline sales. He et al. (2016) studied two models about customer free-riding and non-free-riding behaviors under dual channels, and compared the carbon emissions of life cycle products in a closed-loop supply chain. The study found that manufacturers benefited from customer free-riding, but increased carbon emissions throughout the supply chain. Most of the effects of consumer free riding on dual channels are negative, but a few researchers hold the opposite opinion. Liu et al. (2020) established and compared four kinds of Stackelberg game models. In these models, the online channel and offline channel cooperate through a display showroom. The results show that regardless of the kind of channel structure, a display showroom can generate benefits for the manufacturer, the retailer and the whole omni-channel supply chain. Viejo-Fernández et al. (2020) analyze that customers do not go to experience the store rather than purchasing directly through online channels, they need to pay a large amount of money, so showrooming has a positive effect on customers. In the above studies, the customer free riding behaviors are all occurred in the traditional dual channels. In this paper, we introduce showrooming phenomenon that occurs in multi-channels.

\subsection{Sales Effort}

When customers are shopping, besides the price factor, the sales effort of physical stores will also affect the customers' purchase behavior. Retailers' sales efforts, such as advertising, discounts, free gifts, membership card points and exhibitions etc. will affect the demand between among channels. Therefore, this paper adds sales effort to the basic demand model. For example, Taylor (2002) believed that retailers' sales effort will promote the increase of market demand. Ranjan \& Jha (2019) researched in the dual channel supply chain, and established the centralized model, the decentralized model and the coordination model respectively to analyze of the retailer's sales effort decision variables. Wang \& Song (2019) 
based on Ranjan \& Jha (2019), studied the impact of sales efforts on results under uncertain demand conditions. Li et al. (2019a) studied the comparison and analysis of some key parameters between dual channels without service effort strategy, ex-ante service effort strategy and ex-post service effort strategy. The comparison shows that the retailer's service effort strategy after the manufacturer is better than that before the manufacturer, and the manufacturer and the retailer gain the most revenue in the ex-post service effort strategy. Tian et al. (2020) studied the sales efforts in the Stackelberg dynamic game in the multi-channel supply chain and analyzes its complexity. Yang et al. (2017) proposed in the agricultural supply chain, the market demand depends on the sales effort, which both the optimal initial order quantity and the optimal option quantity increase with the sales effort. Yang \& Tang (2019) presented the channel selection of three modes, such as retail mode, dual channel mode and $\mathrm{O} 2 \mathrm{O}$ mode, the optimal decision-making of fresh products with and without freshness-keeping effort is studied. The more sensitive customers are to product freshness, the more efforts retailers make to maintain freshness that will benefit all members of the supply chain. Friend et al. (2020) have found that sales efforts rely on strategic insights provided by services, which will strengthen co-creation contracts. In the past, literature researchers always considered how sales efforts affect the company's operational decision-making. Few literatures study how retailers' sales efforts mitigate the negative impact of showrooming.

\subsection{Coordination Mechanism}

The essence of supply chain coordination is to distribute profits reasonably between manufacturers and retailers and to optimize the supply chain profits. How to coordinate to improve the efficiency of supply chain is the priority of supply chain management. This is because the supply chain contains many independent individuals. Each member maximizes their own benefits, which will often cause "double marginal effect" that makes it impossible to achieve supply chain coordination under decentralized decision. Therefore, it is necessary to establish a reasonable coordination mechanism to optimize the decentralized model. For example, Yang \& Chen (2018) built and compared four schemes such as RevenueSharing scheme, Cost-Sharing scheme, both scheme and Neither scheme. The author thought that above contracts will encourage manufacturers to reduce carbon emissions, but the incentive effect of revenue-sharing contract is better than cost-sharing contract. Modak \& Kelle (2019) put forward a dual-channel supply chain that takes into account the uncertain demand of price and lead time, a coordination mechanism is used to control inventory management. Qian et al. (2020) came up with a two-stage sustainable supply chain composed of a manufacturer with a sense of social responsibility and a retailer with a sense of fairness, then compares the impact of two cooperative contracts such as wholesale price and two-part contract and two non-cooperative contracts such as Nash equilibrium and bargaining on supply chain performance. Zhang et al. (2020) studied 
the smart cell phone batteries quality and price in defective item return and waste product return, and used revenue-sharing contract to motivate retailer's efforts in recycling waste products. Zhao et al. (2020) proposed to coordinate the price and quality aspects of the fashion supply chain under demand disruptions, and argued that profit sharing contracts have greater advantages than linear quantity discount contracts in some cases. Choi \& Liu (2019) conducted the optimal advertisement strategy about risk attitudes of the luxury fashion brand, the coordination mechanism overcomes the double marginal effect in each risk attitude case. In the existing research papers, there have been many different contracts, such as wholesale price contract, two-part tariff contract, revenue sharing contract and quantity elasticity contract and so on. In the past, the coordination mechanism to solve dual channel showrooming was always cost sharing contract. Because retailers have made sales efforts, manufacturers have to split the costs for the customer free riding behavior. However, in the multi-channel fashion supply chain, the company should give priority to the retained earnings to ensure that it does not lose money, and then realize the long-term maximization of enterprise value through the distribution of residual profits between a retailer and a manufacturer. Therefore, this paper uses the SPS to coordinate the channel supply chain.

The key feature of this research is the influence of customers' showrooming on the performance of the manufacturer and the retailer in the multi-channel apparel supply chain rather than in dual channel. This paper also studies the retailer's sales effort as the main non-price factor that affects customers' showrooming behavior. In addition, based on the centralized model and the decentralized model, the SPS contract is used to coordinate the retailer's sales effort and supply chain profit.

\section{Problem Description and Notations}

A multi-channel apparel supply chain model consisting of a single manufacturer and a single retailer is considered in this paper. Manufacturers directly sell products online and wholesale products to retailers. At the same time, retailers sell their products through online and offline channels, as shown in Figure 1. First, the manufacturer sells the product to the consumer directly at price online $p_{m o}$ and sells the product to the retailer at wholesale price $w$. Then, the retailer determines the offline sales price $p_{r f}$ and online price $p_{r o}$ according to the wholesale price $w$. The relevant parameters used in this paper are presented in Table 1. In the actual purchase process, some consumers are used to try on clothes in physical store and obtain the information about clothes before shopping, to avoid the frequent return and exchange of online purchase. After getting the price information of each channel, customers usually turn to the channel with lower price. To retain these customers, retailers also add online channels. In the original dual channel clothing supply chain, the addition of retailers' online channels will not only compete with offline channels, but also with online channels. Compared with the classic dual channel model, the multi-channel model leads to a wider 
coverage of customers, more fierce competition of price, and more common free riding behavior in the apparel industry. For example, in real life, customers try on the clothes and choose the suitable size in clothing retail entity shop, then they will compare the online prices between the manufacturer and the retailer through mobile phones so that they will choose one of the two channels to purchase. In the past, there was only one manufacturer's online channel, so they had to choose it if they didn't satisfy with offline price. However, if only one of the online prices is lower than the offline price in the multi-channels, customers will pay in the online channel. The reason that showrooming is more popular in the multi-channels is that there are more options are available for hesitant customers to select.

Table 1. List of notations and descriptions.

\begin{tabular}{|c|c|}
\hline Notation & description \\
\hline$c$ & Manufacturing cost \\
\hline$w$ & Wholesale price \\
\hline$a$ & Basic potential market demand \\
\hline$b_{1}$ & Price competition parameter (online-offline) \\
\hline$b_{2}$ & Price competition parameter (online-online) \\
\hline$p_{m o}$ & Price online of manufacturer \\
\hline$p_{r f}$ & Price offline of retailer \\
\hline$p_{r o}$ & Price online of retailer \\
\hline$\theta$ & Showrooming effect coefficient \\
\hline$t$ & Manufacturer's share in the online market \\
\hline$s$ & Sales effort level \\
\hline$k$ & Sales effort cost coefficient \\
\hline$\lambda$ & Bargaining power of manufacturer \\
\hline$\beta$ & Bargaining power of retailer \\
\hline$D_{m o}$ & Online demand for manufacturer \\
\hline$D_{r f}$ & Offline demand for retailer \\
\hline$D_{r o}$ & Online demand for manufacturer \\
\hline$\pi_{m}$ & Manufacturer profit \\
\hline$\pi_{r}$ & Retailer profit \\
\hline$\pi_{s c}^{c}$ & Supply chain profit in centralized mode \\
\hline$\pi_{s c}^{d}$ & Supply chain profit in decentralized mode \\
\hline$\pi_{s c}^{c o}$ & Supply chain profit in coordination mode \\
\hline
\end{tabular}




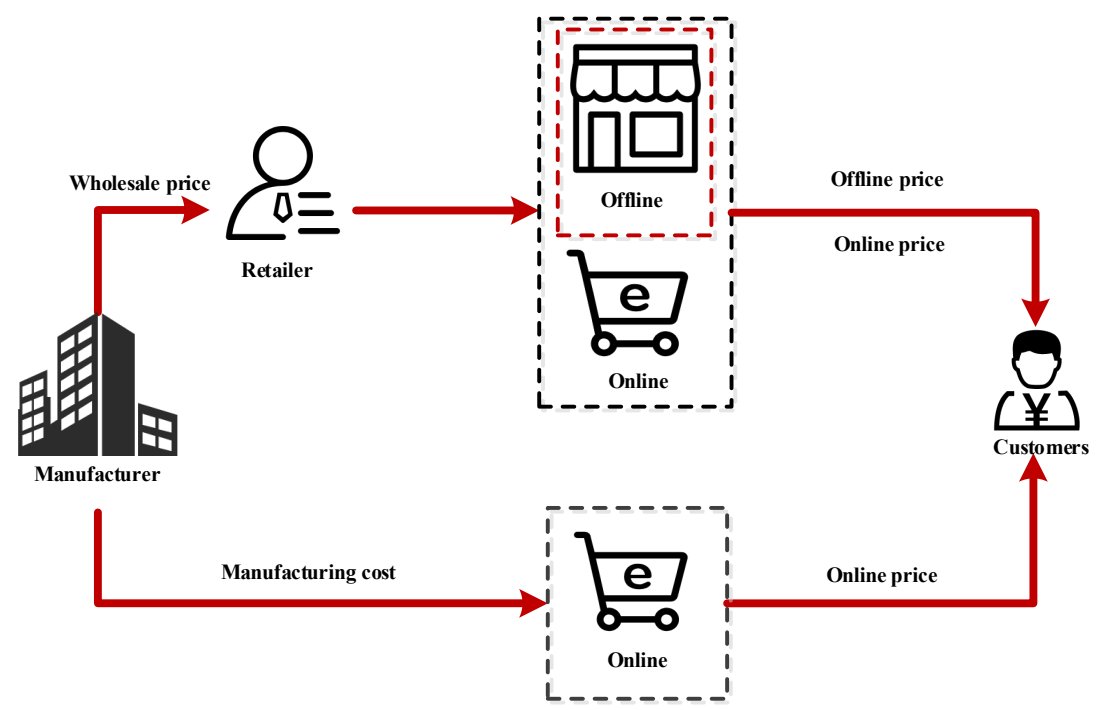

Figure 1. Multi-channel apparel supply chain structure.

Hypothesis 1: Assume that manufacturer and retailer all profit per product, so the price needs to satisfy $\min \left\{p_{m o}, p_{r f}, p_{r o}\right\}>w>c$.

Hypothesis 2: Because the two channels have their own advantages, for example, online shopping is more convenient and physical shopping experience is better. Hence suppose that consumers have no channel preference at first, and the initial potential market demand is $a$.

Hypothesis 3: Retailers' brick-and-mortar stores have made sales effort, so this paper considers that the cost of retailer's sales effort is $C(s)=\frac{1}{2} * k * s^{2}$ (Desiraju \& Moorthy, 1997; Tsay \& Agrawal, 2000; Saha, 2013), which $s$ is the sales effort level, $k$ is the sales effort cost coefficient, and the sales effort cost increases with the sales effort.

Hypothesis 4: Because in the apparel supply chain, from the early stage of costume design, fabric purchasing, apparel manufacturing, until the sales and other links, which are made by manufacturer (Şen, 2008). The retailer is downstream of the manufacturer and needs to cooperate with it. Therefore this paper assumes that the manufacturer is the leader of the Stackelberg game and the retailer is its follower.

According to the basic demand function (McGuire \& Staelin, 1983; Moon et al., 2018), this paper introduces sales effort, the multi-channel demand functions are given by:

$$
\begin{gathered}
D_{m o}=a-p_{m o}+b_{1}\left(p_{r f}-p_{m o}\right)+b_{2}\left(p_{r o}-p_{m o}\right)+t \theta s \\
D_{r f}=a-p_{r f}+b_{1}\left(p_{m o}-p_{r f}\right)+b_{1}\left(p_{r o}-p_{r f}\right)+(1-\theta) s \\
D_{r o}=a-p_{r o}+b_{1}\left(p_{r f}-p_{r o}\right)+b_{2}\left(p_{m o}-p_{r o}\right)+(1-t) \theta s
\end{gathered}
$$

where $b_{1}$ is the competition coefficient between online and offline channels, the greater $b_{1}$ is, the more intense the competition between online and offline channels is. $b_{2}$ is the competition coefficient between online channels of manu- 
facturers and retailers, the greater $b_{2}$ is, the more intense the competition between online channels of manufacturers and retailers is, and $0<b_{1}<1,0<b_{2}<1$, to ensure the downward inclination of demand function. $t$ is manufacturer's share in the online market, $1-t$ is retailer's share in the online market. The larger $t$ is, the more customers are willing to choose manufacturers' online channels, and only a few people will choose retailers' online channels. $\theta$ is the showrooming effect coefficient, reflecting the dependence degree between retailers and the manufacturer. The larger $\theta$ is, the more serious the free riding problem is. $s$ is the sales effort level paid by retailers, which will increase the demand of the retailer and the manufacturer.

$$
\begin{gathered}
\pi_{m}=\left(p_{m o}-c\right) D_{m o}+(w-c)\left(D_{r f}+D_{r o}\right) \\
\pi_{r}=\left(p_{r f}-w\right) D_{r f}+\left(p_{r o}-w\right) D_{r o}-\frac{1}{2} \kappa s^{2}
\end{gathered}
$$

\section{Models}

\subsection{Optimal Decision under Centralized Mode}

Centralized strategies in the apparel supply chain environment require manufacturers and retailers to work more closely to create profits. The centralized model studies the overall profit of the supply chain from a system perspective. The supply chain profit is the sum of the manufacturer profit and the retailer profit. The sales price and the sales effort level are uniformly set by centralized decision makers. The centralized decision variables in the apparel supply chain include $p_{m o}, p_{r f}, p_{r o}$ and $s$. By getting an equilibrium solution to the decision variables, the profit of the entire supply chain is optimized.

In the centralized mode, the game sequences of the manufacturer, the retailer and consumers are: 1) centralized decision makers determine the sales effort level; 2) centralized decision makers determine the sales price; 3) consumers decide to buy in the right channel. Figure 2 illustrates this decision process.

The supply chain profit under the centralized mode is as follows:

$$
\pi_{s c}=\pi_{m}+\pi_{r}=\left(p_{m o}-c\right) D_{m o}+\left(p_{r f}-c\right) D_{r f}+\left(p_{r o}-c\right) D_{r o}-k s^{2} / 2
$$

Proposition 1. The feasible region of equilibrium price is not straightforward. When Hessian matrix is negative, it needs to meet the conditions of $\left(1+b_{1}+b_{2}\right)\left(1+2 b_{1}\right)>b_{1}^{2}$ and $3 b_{1}^{2}+4 b_{1}+2 b_{2}+6 b_{1} b_{2}+1>0 . \pi_{s c}$ is the joint concave in $p_{m o}, p_{r f}, p_{r o}$, thus we can maximize profit $\pi_{s c}$. The specific steps are as follows.

First, we find the first-order derivative of $\left(1+b_{1}+b_{2}\right)\left(1+2 b_{1}\right)>b_{1}^{2}, \pi_{s c}$ with respect to $p_{m o}, p_{r f}$ and $p_{r o}$ respectively and set them to zero, then obtain the sales price.

$$
\begin{gathered}
p_{m o}^{c}=\frac{a+c}{2}+\frac{s b_{1} N+s \theta\left(b_{2}-b_{1}+t M\right)}{2 M N} \\
p_{r f}^{c}=\frac{a+c}{2}+\frac{s\left(1+b_{1}-\theta\right)}{2 M}
\end{gathered}
$$




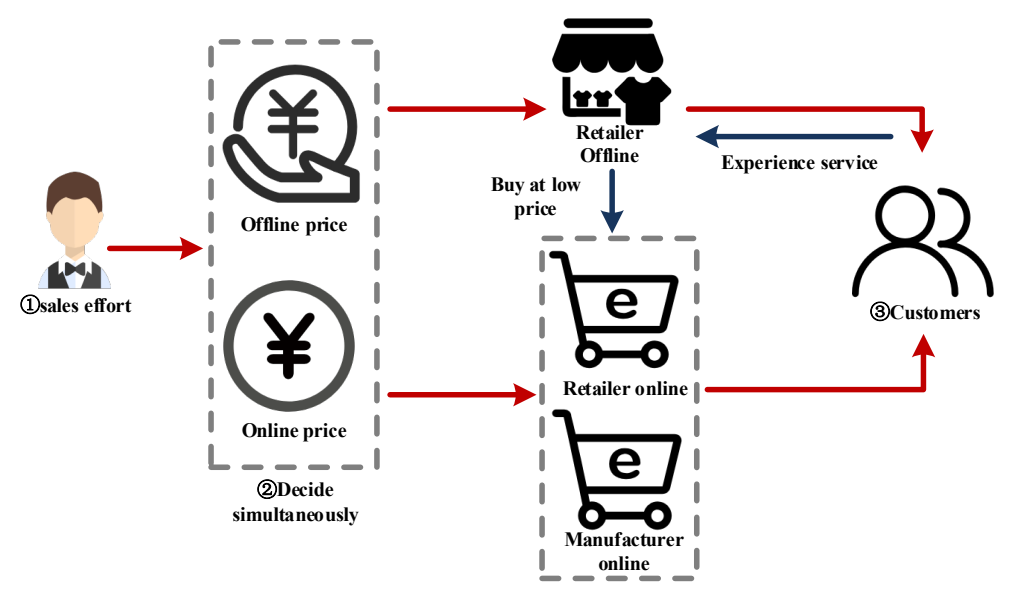

Figure 2. Decision process in the centralized setting.

$$
\begin{gathered}
p_{r o}^{c}=\frac{a+c}{2}+\frac{s b_{1} N+s \theta(P-t M)}{2 M N} \\
M=1+3 b_{1}, \quad N=1+b_{1}+2 b_{2}, \quad P=1+2 b_{1}+b_{2}
\end{gathered}
$$

Proposition 2. From the above formula, we can see $p_{r f}^{c}>\max \left\{\frac{a+c}{2}, c\right\}$; when $t \geq 0.5$, we can get $p_{m o}^{c} \geq p_{r o}^{c}$; when $t<0.5$, we can get $p_{m o}^{c}<p_{r o}^{c}$, indicating that in the centralized mode, the retailer's offline price depends on the production cost and potential market demand. When more customers choose manufacturer's online channels, the retailer has to set lower prices than manufacturer in order to attract more customers, vice versa.

$$
\frac{\partial \pi_{s c}}{\partial s^{2}}=(1-\theta)^{2}+\theta^{2}\left(1-2 t+2 t^{2}\right)
$$

when

$$
\begin{aligned}
& +b_{1}\left(2(1-\theta)+3\left(1-2 t+2 t^{2}\right) \theta^{2}+2 b_{2}(1-6 \kappa)-8 \kappa\right), \pi_{s c} \text { is a strict- } \\
& +b_{1}^{2}(1-6 \kappa)+b_{2}\left(2-4 \theta+3 \theta^{2}-4 \kappa\right)-2 \kappa<0
\end{aligned}
$$

ly concave function of $s$. Then following the backward induction, the above Equations (7) (8) (9) is introduced into $\pi_{s c}$, and the first-order of $\pi_{s c}$ with respect to $s$ is used to get the equilibrium solution of sales effort level $s$.

$$
s^{c^{*}}=\frac{(a-c) M N}{\left(2 \theta-b_{1}-1\right) N-\left[2 M\left(t^{2}-t\right)+3\left(b_{1}+b_{2}\right)+2\right] \theta^{2}+2 \kappa M N}
$$

Taking $s^{c^{*}}$ into Equations (7) (8) (9), we can get $p_{m o}^{c^{*}}, p_{r f}^{c^{*}}, p_{r o}^{c^{*}}$ :

$$
\begin{aligned}
& p_{m o}^{c^{*}}=\frac{a+c}{2}+\frac{\left[b_{1} N+\theta\left(b_{2}-b_{1}+t M\right)\right](a-c)}{2\left\{\left(2 \theta-b_{1}-1+2 \kappa M\right) N-\left[2 M\left(t^{2}-t\right)+3\left(b_{1}+b_{2}\right)+2\right] \theta^{2}\right\}} \\
& p_{r f}^{c^{*}}=\frac{a+c}{2}+\frac{\left(1+b_{1}-\theta\right)(a-c) N}{2\left\{\left(2 \theta-b_{1}-1+2 \kappa M\right) N-\left[2 M\left(t^{2}-t\right)+3\left(b_{1}+b_{2}\right)+2\right] \theta^{2}\right\}} \\
& p_{r o}^{c^{*}}=\frac{a+c}{2}+\frac{\left[b_{1} N+\theta(P-t M)\right](a-c)}{2\left\{\left(2 \theta-b_{1}-1+2 \kappa M\right) N-\left[2 M\left(t^{2}-t\right)+3\left(b_{1}+b_{2}\right)+2\right] \theta^{2}\right\}}
\end{aligned}
$$


According to the optimal solution of the above decision variables $s^{c^{*}}, p_{m o}^{c^{*}}, p_{r f}^{c^{*}}, p_{r o}^{c^{*}}$, which is brought into Equation (1)-(6), the optimal demand $D_{m o}^{c^{*}}, D_{r f}^{c^{*}}, D_{r o}^{c^{*}}$ and optimal profit $\pi_{m}^{c^{*}}, \pi_{r}^{c^{*}}, \pi_{s c}^{c^{*}}$ can be obtained under the centralized mode of clothing supply chain.

\subsection{Optimal Decision in Decentralized Mode}

Under the decentralized model, the manufacturer's profit and the retailer's profit are optimized. In the decentralized mode, the game sequence of the manufacturer, the retailer, and consumers is: 1) the retailer determines the sales effort level; 2) the manufacturer determines the wholesale price and the manufacturer's online price; 3 ) the retailer based on the wholesale price and online prices of the manufacturer, and then determine retail's offline prices and online prices; 4) consumers choose the appropriate channels to buy. Manufacturer's decision on product wholesale prices and online prices has an indirect impact on the retailer's revenue. Retailers' sales effort level and retail prices have an impact on manufacturer's revenue. Under the mutual influence of prices, manufacturers and retailers, as independent individuals, are pursuing the maximization of their own profits. Figure 3 illustrates this decision process.

\subsubsection{Retailer's Best Price Response}

The retailer's best price response strategy is obtained by standard backward induction.

Proposition 3: when Hessian matrix is negative, the condition of $4 b_{1}^{2}+12 b_{1}+4 b_{2}+8 b_{1} b_{2}+4>0$ must be satisfied. Retailer's profit $\pi_{r}$ is a joint concave function with respect to $p_{r f}$ and $p_{r o}$, and $\pi_{r}^{d}$ obtains the maximum value. The specific steps are as follows.

First, the first-order derivative of $p_{r f}$ and $p_{r o}$ is obtained by Equation (5), and the retailer's optimal response function is obtained.

$$
p_{r f}^{d}=\frac{b_{1} N p_{m o}+(M+H) w+a P+J_{S}}{2(M+H)}
$$

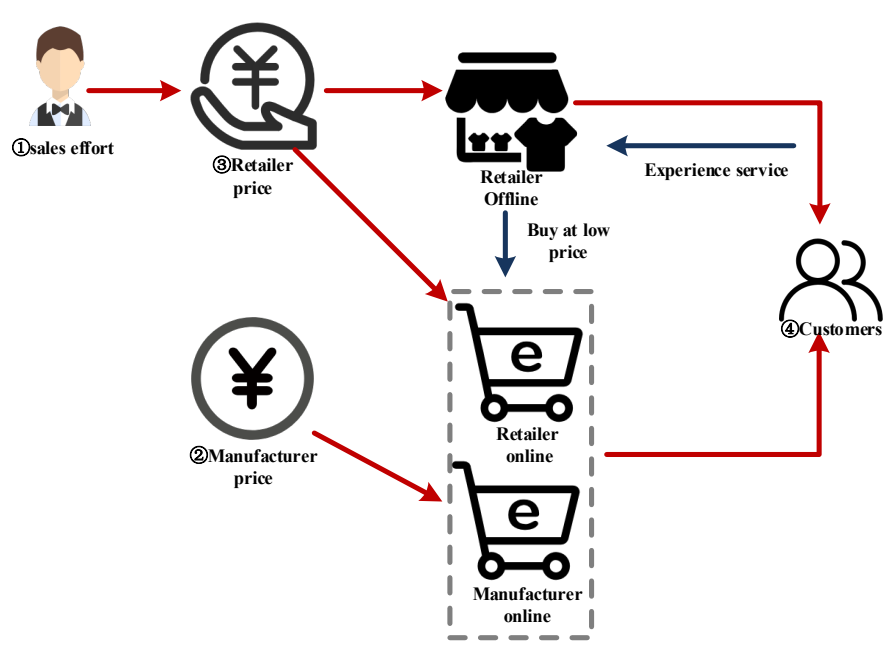

Figure 3. Decision process in the decentralized setting. 


$$
\begin{gathered}
p_{r o}^{d}=\frac{a M+H p_{m o}+(M+H) w+K s}{2(M+H)} \\
H=b_{1}^{2}+b_{2}+2 b_{1} b_{2}, \quad J=\left(1+b_{2}\right)(1-\theta)+b_{1}(1-t \theta), \quad K=\theta(1-t)+b_{1}(1+\theta-2 t \theta)
\end{gathered}
$$

\subsubsection{Manufacturer's Price Decision}

When Equation (14) and Equation (15) are introduced into Equation (4), it is obvious that $\pi_{m}$ satisfies the Hessian matrix negative definite condition

$H=\left[\begin{array}{cc}\frac{\partial^{2} \pi_{m}}{\partial w^{2}} & \frac{\partial^{2} \pi_{m}}{\partial w \partial p_{m o}} \\ \frac{\partial^{2} \pi_{m}}{\partial p_{m o} \partial w} & \frac{\partial^{2} \pi_{m}}{\partial p_{m o}^{2}}\end{array}\right]$, i.e. the first-order determinant

$\frac{\partial^{2} \pi_{m}}{\partial w^{2}}=-2\left(2+7 b_{1}+5 b_{1}^{2}+b_{1}^{3}+3 b_{2}+8 b_{1} b_{2}+3 b_{1}^{2} b_{2}+b_{2}^{2}+2 b_{1} b_{2}^{2}\right)<0$ and the second-order determinant

$|H|=4+6 b_{1}^{3}+10 b_{2}+5 b_{2}^{2}+3 b_{1}^{2}\left(7+6 b_{2}\right)+2 b_{1}\left(9+17 b_{2}+6 b_{2}^{2}\right)>0$. Manufacturer's profit $\pi_{m}$ is a joint concave function of $w$ and $p_{m o}$, and $\pi_{m}^{d}$ obtains the maximum value.

We find the first-order derivative of $\pi_{m}$ with respect to $p_{m o}$ and $w$ respectively and set them to zero, then obtain the wholesale price and manufacturer's online price.

$$
\begin{array}{r}
(a+c)\left(4+6 b_{1}^{3}+3\left(7+6 b_{2}\right) b_{1}^{2}+2\left(9+17 b_{2}+6 b_{2}^{2}\right) b_{1}+5 b_{2}^{2}+10 b_{2}\right) \\
w^{d}=\frac{\left(\begin{array}{l}
\left.2 b_{1}^{3}+\left(8+6 b_{2}-(1+t) \theta\right) b_{1}^{2}+\left(4 b_{2}^{2}+(13-5 t \theta) b_{2}-6 t \theta+8\right) b_{1}\right) \\
+(1+\theta) b_{2}^{2}+2(2-t \theta) b_{2}+2-2 t \theta
\end{array}\right)}{2\left(4+6 b_{1}^{3}+3\left(7+6 b_{2}\right) b_{1}^{2}+2\left(9+17 b_{2}+6 b_{2}^{2}\right) b_{1}+5 b_{2}^{2}+10 b_{2}\right)} \\
+(a+c)\left(4+6 b_{1}^{3}+3\left(7+6 b_{2}\right) b_{1}^{2}+2\left(9+17 b_{2}+6 b_{2}^{2}\right) b_{1}+5 b_{2}^{2}+10 b_{2}\right) \\
p_{m o}^{d}=\frac{\left(\begin{array}{l}
\left.2 b_{1}^{3}+\left(6+6 b_{2}-\theta+5 t \theta\right) b_{1}^{2}+\left(3+9 b_{2}+4 b_{2}^{2}-2 \theta+13 t \theta+7 b_{2} t \theta\right) b_{1}\right) \\
+(1+\theta) b_{2}^{2}+(1+2 \theta+3 t \theta) b_{2}+4 t \theta
\end{array}\right)}{2\left(4+6 b_{1}^{3}+3\left(7+6 b_{2}\right) b_{1}^{2}+2\left(9+17 b_{2}+6 b_{2}^{2}\right) b_{1}+5 b_{2}^{2}+10 b_{2}\right)}
\end{array}
$$

$w^{d}$ and $p_{m o}^{d}$ above are the price decision variables of manufacturers. Then $w^{d}$ and $p_{m o}^{d}$ are inversely brought into the retailer's price decision Equation (14) and Equation (15), and new optimal solutions $p_{r f}^{d 1}$ and $p_{r o}^{d 1}$ are obtained.

\subsubsection{Retailer's Optimal Sales Effort Level}

The retailer determines the level of sales effort $s$ to maximize its retailer profits. First, the manufacturer's prices $w^{d}$ and $p_{m o}^{d}$ and the retailer prices $p_{r f}^{d 1}$ and $p_{r o}^{d 1}$ are currently brought into $\pi_{r}$, and then $\pi_{r}$ takes a first-order partial derivative of $s$ and lets the derivatives be equal to zero, we obtain $s^{d^{*}}$.

Taking $s^{d^{*}}$ into the price optimal solution of manufacturer and retailer's price decision, we can get $w^{d^{*}}, p_{m o}^{d^{*}}, p_{r f}^{d^{*}}, p_{r o}^{d^{*}}$; at the same time, taking $s^{d^{*}}, w^{d^{*}}, p_{m o}^{d^{*}}, p_{r f}^{d^{*}}, p_{r o}^{d^{*}}$ into Equations (1)-(6), we can get the optimal solution 
demand $D_{m o}^{d^{*}}, D_{r f}^{d^{*}}, D_{r o}^{d^{*}}$ and optimal profit $\pi_{m}^{d^{*}}, \pi_{r}^{d^{*}}, \pi_{s c}^{d^{*}}$ in decentralized mode.

\subsection{SPS Coordination Mechanism}

Because of the double marginalization, the supply chain profit in the centralized model is higher than that in the decentralized model (Ranjan \& Jha, 2019), so it is necessary to use the coordination model to optimize the former supply chain model. In this paper, the SPS coordination mechanism is used to coordinate the profits of both sides through the manufacturer's bargaining power $\alpha$ and the retailer's bargaining power $\beta(0<\alpha+\beta<1)$. The coordination of surplus profit is determined by the negotiation ability of both parties. The higher $\alpha$ means the stronger negotiation ability of the manufacturer, and the manufacturer gets more surplus profit. The higher $\beta$ means the retailer gets more surplus profit. As required, the coordination model is as follows:

Maximize $\pi_{s c}^{c o}=\pi_{m}+\pi_{r}=\left(p_{m o}-c\right) * D_{m o}+\left(p_{r f}-c\right) * D_{r f}+\left(p_{r o}-c\right) * D_{r o}-\frac{1}{2} * \kappa * s^{2}$

Subject to

$$
\begin{aligned}
& \pi_{m}^{c o}=\left(p_{m o}-c\right) D_{m o}+(w-c)\left(D_{r f}+D_{r o}\right) \geq \pi_{m}^{d^{*}}+\alpha\left(\pi_{s c}^{c^{*}}-\pi_{s c}^{d^{*}}\right) \\
& \pi_{r}^{c o}=\left(p_{r f}-w\right) D_{r f}+\left(p_{r o}-w\right) D_{r o}-\frac{1}{2} \kappa s^{2} \geq \pi_{r}^{d^{*}}+\beta\left(\pi_{s c}^{c^{*}}-\pi_{s c}^{d^{*}}\right)
\end{aligned}
$$

In the above formula, when the manufacturer (retailer) profit is higher than the sum of the manufacturer (retailer) optimal profit and the residual profit negotiation value, the supply chain profit maximization is achieved. Among them, $\alpha$ represents the proportion of the manufacturer in the surplus profit, and $\alpha\left(\pi_{s c}^{c^{*}}-\pi_{s c}^{d^{*}}\right)$ is the additional profit obtained by the manufacturer through negotiation. $\beta$ represents the proportion of the retailer in the surplus profit, and $\beta\left(\pi_{s c}^{c^{*}}-\pi_{s c}^{d^{*}}\right)$ is the extra profit obtained by the retailer through negotiation. The manufacturer and the retailer bargain with the remaining profits of different channels, and the stronger their ability is, the more profits they get in the profit distribution mechanism.

\section{Sensitivity Analysis}

Parameter $\theta$ and $t$ are the two most important factors that affect supply chain performance. Thus sensitivity analysis mainly studies the influence of showrooming effect coefficient $\theta$ and manufacturer's share in the online market $t$ on the optimal price, sales effort, demand and profit. In order to make this sensitivity analysis more intuitive, black, red and blue lines or surfaces are used to represent the centralized model, decentralized model and the coordinated model respectively.

\subsection{Under the Influence of Showrooming Effect Coefficient}

Under the assumption of $a=200, b_{1}=0.8, b_{2}=0.7, c=20, t=0.5$, $\kappa=0.9, \alpha=\beta=0.35$ three modes are compared and analyzed. In the following figures, the showrooming effect coefficient increases from 0 to 1 at 0.1 inter- 
vals, and study the influence of $\theta$ on decision variables and profits.

Figure 4 shows the effect of showrooming effect coefficient $\theta$ on the optimal sales price of retailer and manufacturer. First of all, from Figure 4, we can see that the sales price in coordination mode is the highest compared with centralized mode and decentralized mode. The possible reason is that under the SPS coordination mechanism, the manufacturer and the retailer achieve a win-win profit by increasing the sales price of each product. Secondly, with the increase of showrooming effect coefficient, the manufacturer's online price and the retailer's online price in the centralized mode increase, while the retailer's offline price begins to decline. The change range of sales price in the decentralized mode is not large, but when the showrooming effect coefficient is 0.27 , the offline price of retailers in the centralized mode is the same as that in the decentralized mode. With the increase of showrooming effect coefficient, the online prices of the manufacturer and the retailer in the coordination mode increase steadily, while the offline prices of retailers decrease at a certain speed. This shows that when a large number of consumers have free riding behavior, physical stores have to reduce prices to attract customers to purchase, which is in line with the actual situation. Third, in terms of price setting, we see that in the decentralized mode, online and offline price of the retailer is around 140, while online price of the manufacturer is significantly lower than that of the retailer which around 110. In the coordination model, the manufacturer's online price is slightly higher than the retailer's online price. In the decentralized model, the manufacturer's price is lower than the retailer's, because there is no middleman for the manufacturer's own operation, so he only needs to consider the production cost, at the same time, he also needs to sell the products to the retailer, and earn the price difference from it, so he can set a lower price to make a huge profit. After coordination, the manufacturer's online price increases instead, and the free riding behavior of customers will be reduced correspondingly, which at the same time protects the benefits of both sides, so as to prevent vicious competition and damage the market rules.

Figure 5 shows that, on the one hand, due to the double marginal effect, the demand of retailers in the centralized mode with line (2) and coordinated mode with line (6) are higher than that in the decentralized mode with line (4). Compared with the decentralized mode of retailer demand with lines (4), the coordinated mode with line (6) is higher. Meanwhile, compared with the decentralized mode of manufacturer demand with lines (3), the coordinated mode with line (5) is lower. Under the coordinated of Figure 4(a), the price set by the manufacturer is higher, so the demand will be reduced, which directly leads to the demand growth of the retailer, which reflects that the retailer makes decision variables according to the manufacturer's response. On the other hand, with the increase of showrooming effect coefficient, the demand change under decentralized mode with line (3) and (4) are not obvious, while the retailer demand under coordinated mode with line (6) decreases, and the manufacturer demand with 
line (5) rises by a small margin. This shows that when the free riding behavior of consumers becomes more and more common, even if retailers introduce the online retail direct channel in the traditional dual channels, it is not necessarily beneficial to retailers.

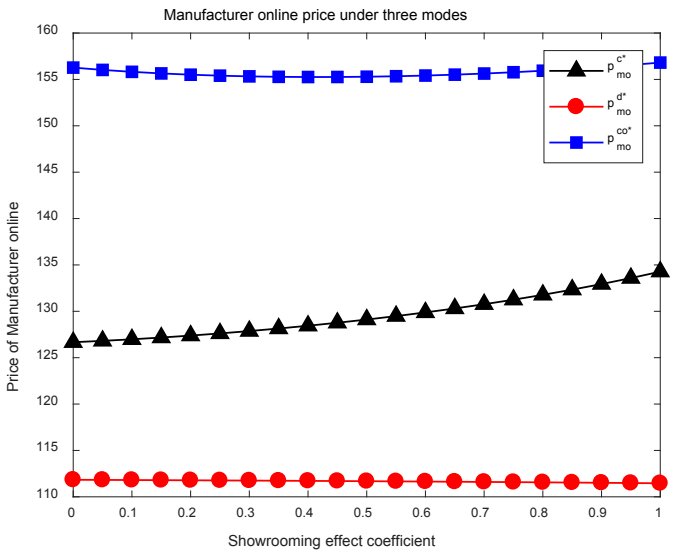

(a)

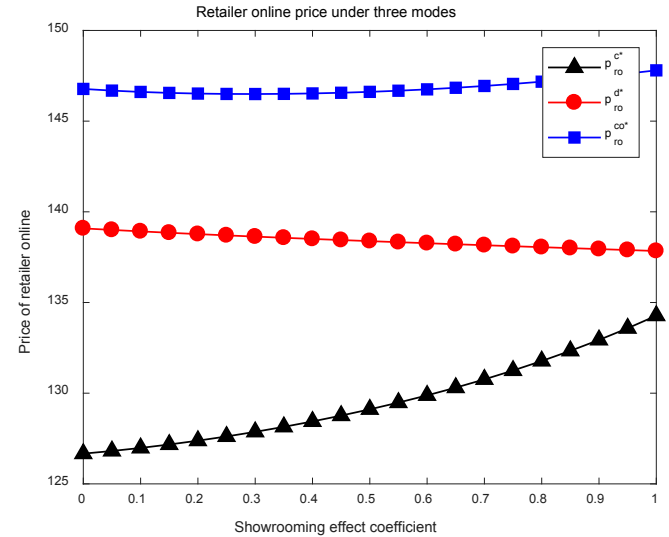

(b)

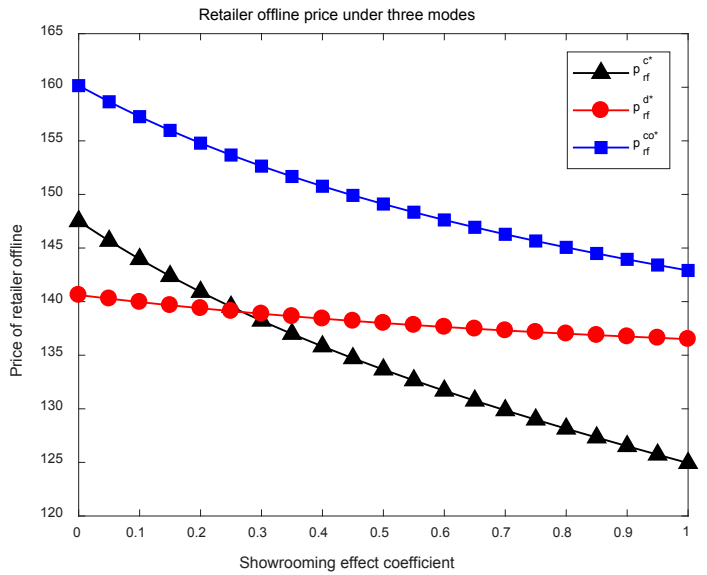

(c)

Figure 4. The effect of showrooming effect coefficient on price. 


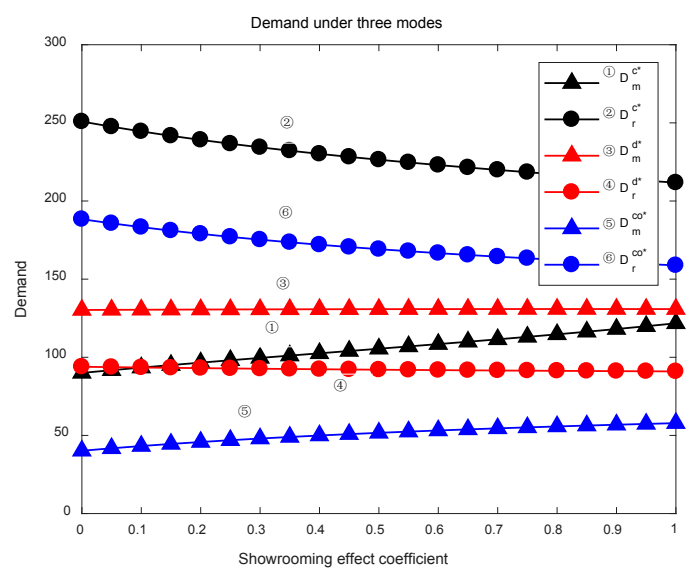

Figure 5. The effect of showrooming effect coefficient on demand.

From the perspective of sales effort level and profit in Figure 6, first of all, it can be seen in Figure 6(c) that compared with the decentralized mode, SPS coordination mechanism can effectively improve sales effort level, while also promoting the growth of total profit. The increase of sales effort level promotes the increase of retailers' demand (see Figure 5), and stimulates retailers to set higher sales price (see Figure 4(b), Figure 4(c)), so as to compensate the extra cost of sales efforts. Secondly, the trend of total profit and sales effort level of supply chain is very similar, which shows that sales effort level in decision variables is one of the key factors affecting profit. In the decentralized model and coordination model, the sales effort level and the total profit of the supply chain decrease with the increase of the showrooming effect coefficient. Because the number of customers choosing online channels increases, the retailer's physical stores will decide to appropriately reduce the sales effort level and the retailer's demand will also decrease (see Figure 5), which shows that the lower sales effort level has a direct negative impact on demand and profit. Finally, with the increase of showrooming effect coefficient, the offline profit of retailers in coordination decreases steadily (see Figure 6(a)), while the online profit of retailers and the profit of manufacturers increase (see Figure 6(a), Figure 6(b)). It can be seen that showrooming is beneficial for retailer online and manufacturer online, but it is disadvantageous for retailers stores even if manufacturers sign a surplus profit-sharing contract with retailers. This shows that the introduction of online channel by retailers can alleviate the loss caused by the increase of free riding behavior.

\subsection{Under the Influence of Both Showrooming Effect Coefficient $\theta$ and Manufacturer's Share in the Online Market $t$}

Under the condition of $a=200, b_{1}=0.8, b_{2}=0.7, c=20, w=50$, $k=0.9, \alpha=\beta=0.35$ the parameter $\theta$ and $t$ increases from 0 to 1 at $0.1 \mathrm{in}$ tervals respectively, and the graph changes are observed. In order to verify the effectiveness of SPS coordination mechanism again, we study the influence of and on relevant decision variables. 


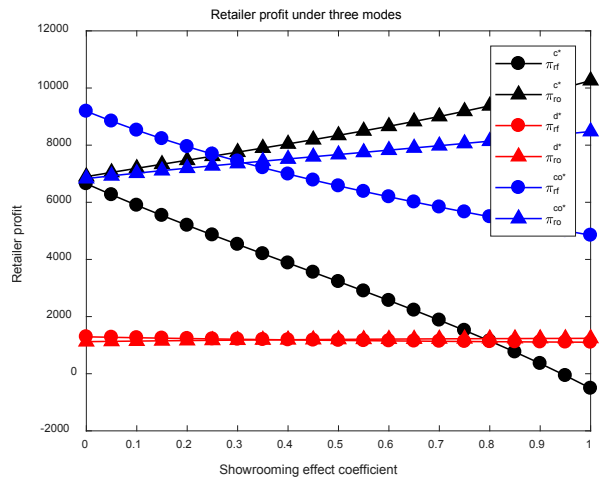

(a)

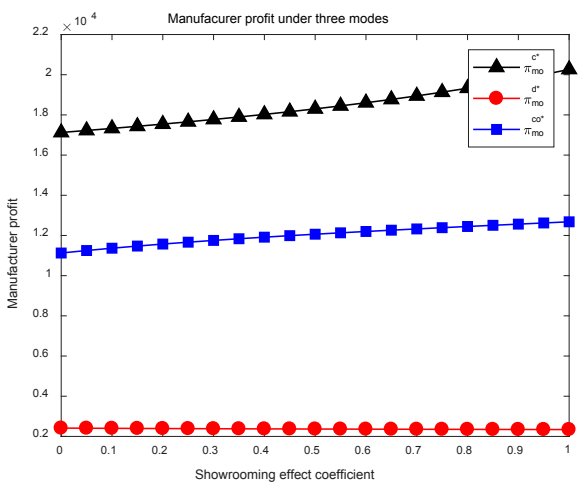

(b)

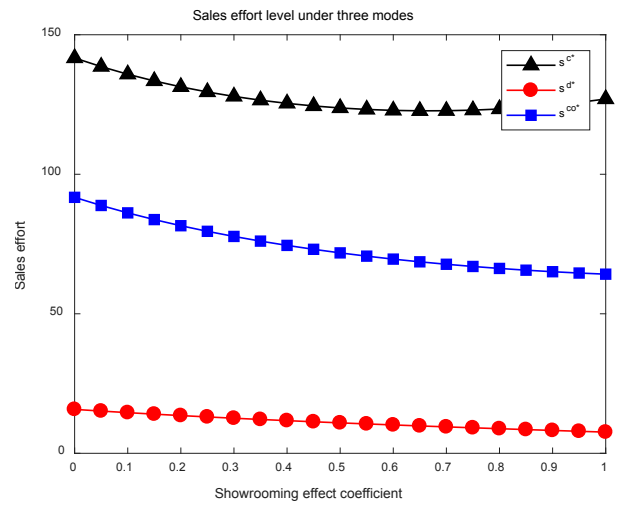

(c)

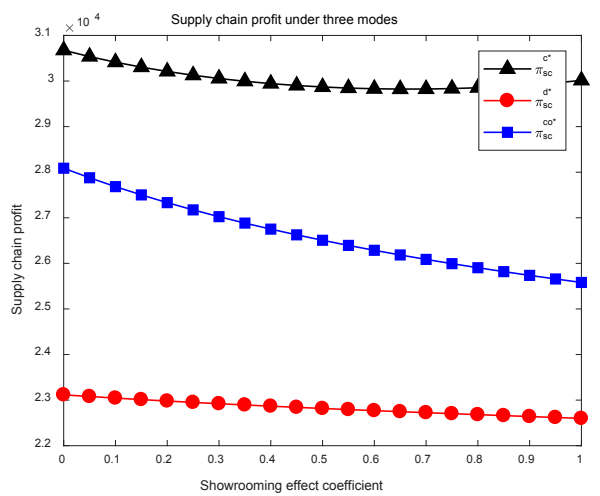

(d)

Figure 6. The effect of showrooming effect coefficient on sales effort and profit. 
From Figures 7(a)-(f), we study the relationship between price and demand under the joint influence of showrooming effect coefficient $\theta$ and $t$. First of all, from the perspective of the three models as a whole, Figures 7(a)-(c) shows that the retail price in the coordination model is higher than that in the decentralized and centralized model, while the demand under the coordination in Figures 7(d)-(f) is not best, even the manufacturer's online demand is the lowest of the three models. This conforms to the market rules. The retail price is inversely proportional to the demand approximately. Secondly, from the trend of the graph, when the $\theta$ is larger and $t$ is smaller in the collaboration model, the increase and decrease of the manufacturer's online price and demand are not obvious (see Figure 7(a), Figure 7(d)); the retailer's offline price and demand are decreasing (see Figure 7(b), Figure 7(e)); the retailer's online price and demand are increasing (see Figure 7(c), Figure 7(f)). This is because when customers are more willing to choose the online channel of retailers after experiencing the service in the physical store, the online channel demand of retailers increases and the demand of physical stores decreases, so the physical store takes price reduction measures to retain the free rider customers. Finally, from the specific value of price and demand, under the influence of $\theta$ and $t$, the manufacturer's online price of coordination mode is maintained at about 160 (see Figure 7(a)), the retailer's offline price is between 145 - 160 (see Figure 7(b)), and the retailer's online price is between 140 - 160 (see Figure $7(\mathrm{c})$ ), but the trend of retailer's online price is opposite to offline price. Interestingly, the online demand of manufacturers is about 40 (see Figure 7(d)), and the retailer's offline demand and online demand are between 70 and 120 (see Figure 7(e), Figure 7(f)). It is observed that when the manufacturer sets the online price is too high, which can cause its demand is significantly less than the retail channel. While the retailer's price is slightly lower than the manufacturer's setting, but the sales volume is increasing rapidly. From this phenomenon, we can see that price has a direct impact on demand.

Figures 8(a)-(e) show sales effort and profit varies with $\theta$ and $t$. They represent the retailer's sales effort, retailer's offline profit, retailer's online profit, manufacturer's profit and total supply chain profit respectively. First, as can be seen from Figure 8(a), the sales effort level is the highest in the centralized mode, followed by the coordinated mode and the lowest is the decentralized mode. It can be seen from Figure 8(b), Figure 8(c) that with the change in $\theta$ and $t$, the online and offline profits of retailers in coordination mode are better than those in decentralized mode. Under the centralized mode, the offline profit of retailers is lower than coordination mode, and the online profit is higher than coordination mode. When the $\theta$ is larger and the $t$ is smaller, the retailer's offline profit decreases while online profit increases. As can be seen from Figure $8(d)$, the manufacturer's profit is generally higher than decentralized mode and slightly lower than centralized mode. With the increase of $\theta$ and $t$, the profit of manufacturers rises rapidly in the centralized mode, and changes slightly in the decentralized mode and coordination mode. As can be seen from Figure 8(e), it 


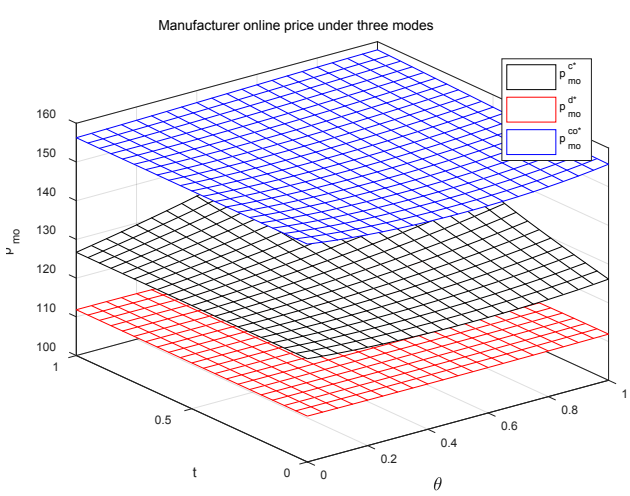

(a)

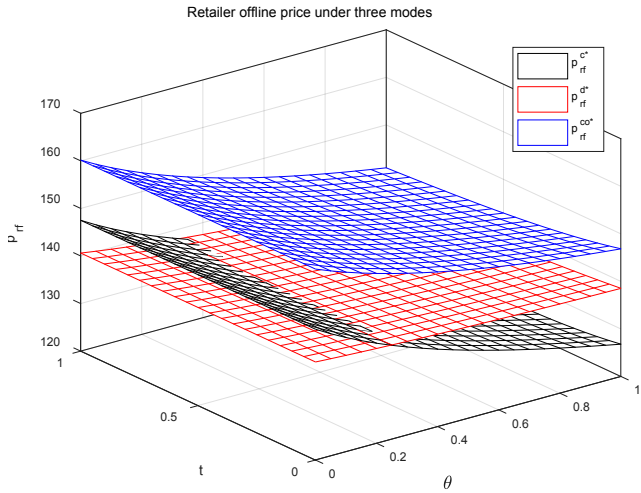

(b)

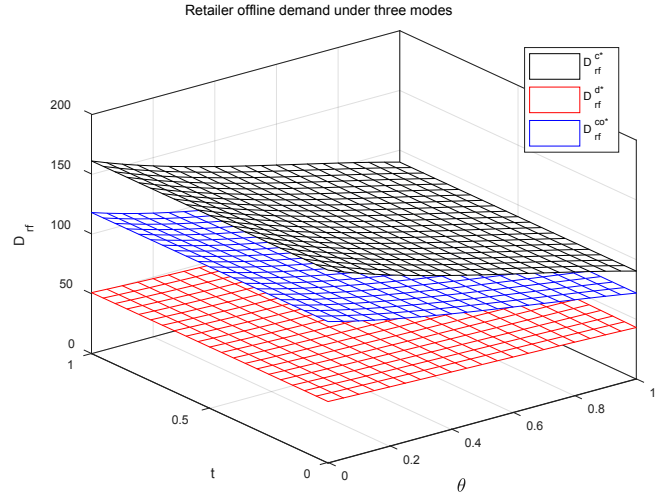

(c)

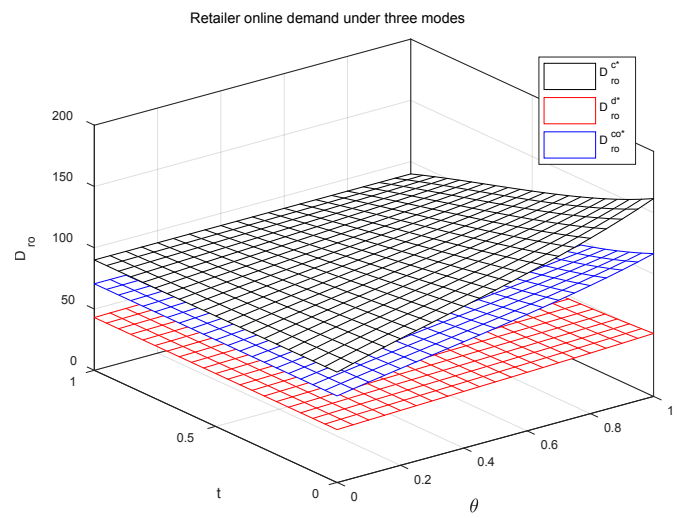

(d) 


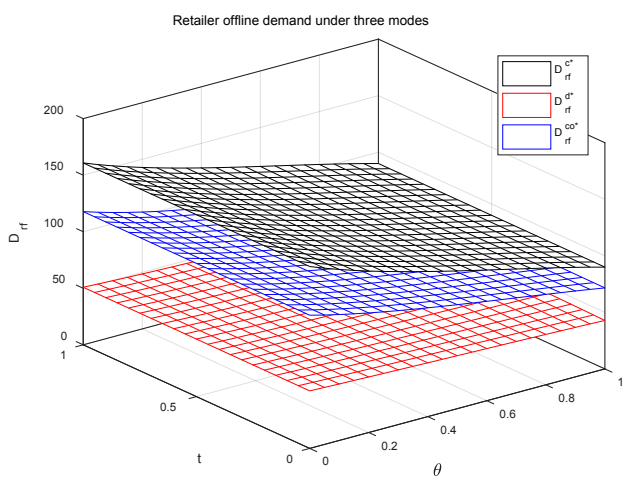

(e)

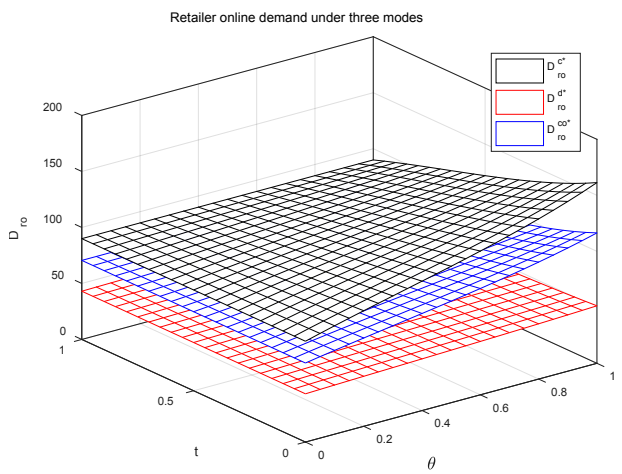

(f)

Figure 7. The effect of $\theta$ and $t$ on price.

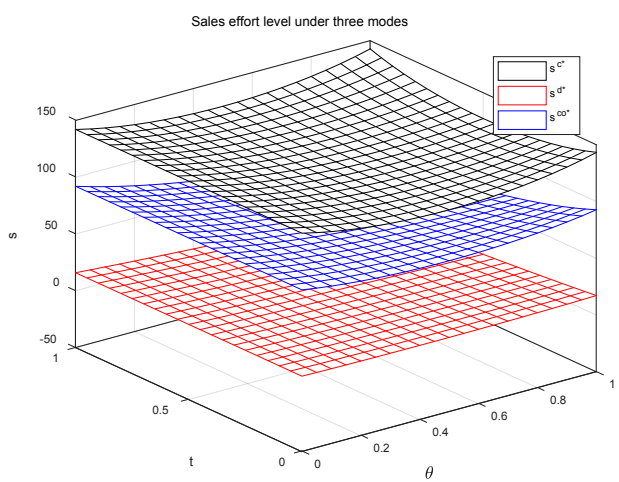

(a)

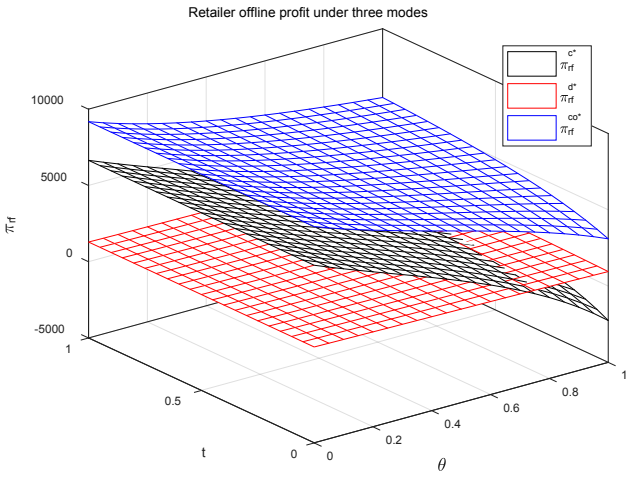

(b) 


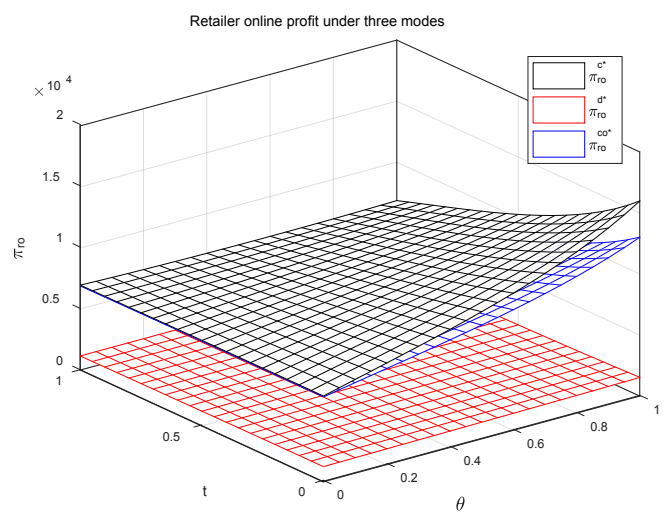

(c)

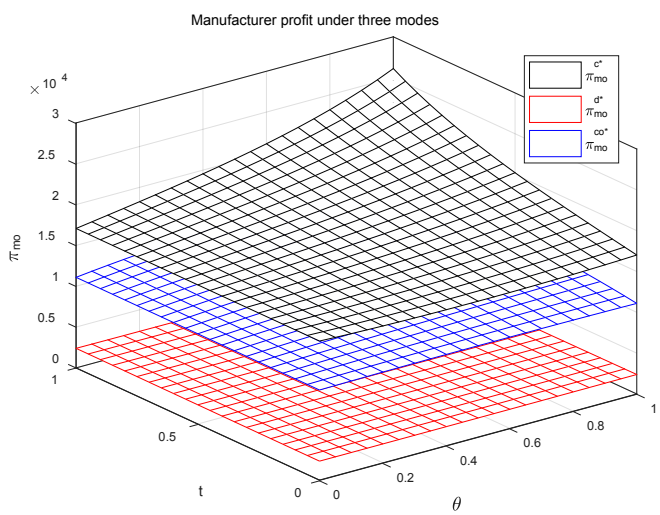

(d)

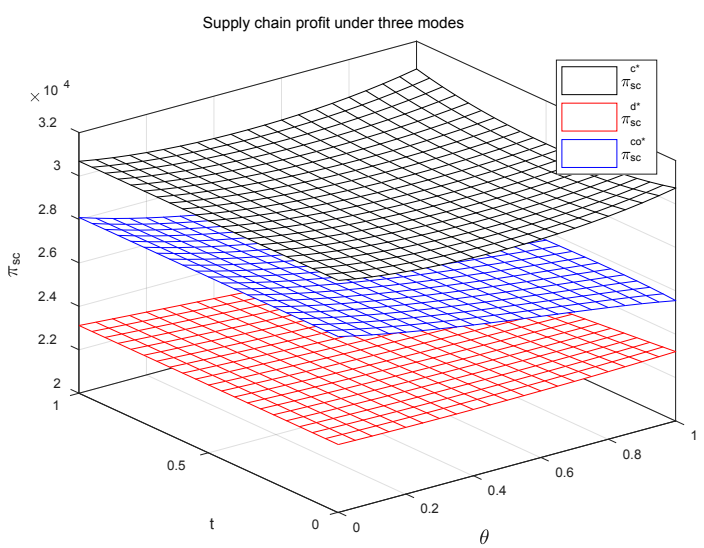

(e)

Figure 8. The effect of $\theta$ and $t$ on price.

is clear that the supply chain profit in the coordination mode is higher than the decentralized mode, but close to the centralized mode. When the $\theta$ is larger and the $t$ is smaller, the supply chain profit under the coordination mode will decrease, while the change range under the centralized mode and decentralized mode is not obvious. As the supply chain profit under coordination becomes smaller, the gap between coordination mode and decentralized mode becomes lessen, and the gap between coordination mode and centralized mode becomes 
larger.

On the one hand, compared with the decentralized model, the retailer in the coordination model provides a higher sales effort level, and the corresponding retailer profits and manufacturer profits are higher, so the overall supply chain profits are higher. This shows that the SPS coordination mechanism under the multi-channel clothing supply chain is an effective method, which can weaken the double marginal benefits between manufacturers and retailers, improve the efficiency of the whole supply chain, and achieve win-win between channel members. On the other hand, as customers choose more online channels of retailers, online profits of retailers will increase, while retailer's offline profits and supply chain profits will decrease. Compared with the free riding behavior of customers under the dual channel mode, this paper adds the online channel of retailers on the basis of the original dual channel supply chain. The free riding of customers will affect the profits of physical stores, but promote the online profits of retailers, alleviate the impact of free riding of customers on retailers, which shows that it is beneficial for retailers to add an online channel.

\section{Conclusion}

This paper mainly studies the influence of free riding behavior on retailer's sales effort and supply chain profit in multi-channel clothing supply chain. This paper first sets up the linear demand function of sales effort and sales price, then obtains the equilibrium solutions under the centralized model and decentralized model respectively by the first-order derivative of Stackelberg game theory, and then uses the coordination mechanism of SPS to achieve the purpose of reasonable distribution of profits. Finally, it analyzes the influence of two factors on decision variables and supply chain performance. Through analysis, we come to the following conclusions:

First of all, SPS coordination model is like cost sharing model, they can coordinate the sales efforts of physical stores and improve the supply chain profits, achieve the economic goal of supply chain profits and meet the benefits of channel members.

Secondly, the higher the showrooming effect coefficient leads to the lower the retailer's sales effort and the supply chain performance. This is mainly because retailers pay the cost of sales efforts, more customers choose to free riding, which leads to the increase in manufacturers' profits and the decrease in retailers' physical stores' profits. Retailers decide to reduce sales efforts to pay less cost, so supply chain profits fall.

Finally, under the free riding behavior of customers, the online channel of retailers has a positive impact on retailers. When more customers choose showrooming, the retailer's offline profit will decline but their online profit will increase, which will benefit the retailer's performance.

The above conclusions have the following the main and important contributions of this research. First of all, this paper verifies that SPS is also applicable to 
the free riding problem of consumers in multi-channel, and has also played a coordinating role in the supply chain. It really fills in channel coordination methods. Therefore, for the sake of fairness, supply chain members are better to sign appropriate contract mechanism to ensure mutual profits. Secondly, in multi-channel, the more showrooming effect, it has a negative effect on the supply chain profit. This proves that the negative effects of free riding will not disappear with the increase of channels. The best way is for physical stores to improve sales efforts or set online price as the same as offline price, try to retain customers and reduce showrooming phenomenon. Finally, the benefits of retailers opening online channel outweigh its disadvantages. The main reason is that it does not need high cost to open online channels.

This paper has limitations in two aspects, which can be explored in future. One limitation is that the present research is based on the certain demand function, but demand is uncertain in reality. In the future work, we will further study the price coordination under the stochastic demand. Another we assume that there are only a retailer and a manufacturer in the market. Nevertheless, in the real life, there are many retailers and manufacturers. In the future work, increasing the number of retailers and manufacturers is also a possible extension to our research. But its profit coordination will be a challenge in these complex scenarios.

\section{Acknowledgements}

This work was supported by the Science and Technology Ministry of China for Cruise Program under grant number 2018-473.

\section{Conflicts of Interest}

The authors declare no conflicts of interest regarding the publication of this paper.

\section{References}

Bai, Q., Chen, M., \& Xu, L. (2017). Revenue and Promotional Cost-Sharing Contract versus Two-Part Tariff Contract in Coordinating Sustainable Supply Chain Systems with Deteriorating Items. International Journal of Production Economics, 187, 85-101. https://doi.org/10.1016/j.ijpe.2017.02.012

Chen, X., Wang, X., \& Chan, H. K. (2016). Channel Coordination through Subsidy Contract Design in the Mobile Phone Industry. International Journal of Production Economics, 171, 97-104. https://doi.org/10.1016/j.ijpe.2015.10.025

Choi, T. M., \& Liu, N. (2019). Optimal Advertisement Budget Allocation and Coordination in Luxury Fashion Supply Chains with Multiple Brand-Tier Products. Transportation Research Part E: Logistics and Transportation Review, 130, 95-107. https://doi.org/10.1016/j.tre.2019.08.009

Desiraju, R., \& Moorthy, S. (1997). Managing a Distribution Channel under Asymmetric Information with Performance Requirements. Management Science, 43, 1628-1644. https://doi.org/10.1287/mnsc.43.12.1628

Friend, S. B., Malshe, A., \& Fisher, G. J. (2020). What Drives Customer Re-Engagement? 
The Foundational Role of the Sales-Service Interplay in Episodic Value Co-Creation. Industrial Marketing Management, 84, 271-286. https://doi.org/10.1016/j.indmarman.2019.07.012

Fu, H., \& Ma, Y. (2019). Optimization and Coordination of Decentralized Supply Chains with Vertical Cross-Shareholding. Computers \& Industrial Engineering, 132, 23-35. https://doi.org/10.1016/j.cie.2019.04.009

Guo, S., Choi, T. M., \& Shen, B. (2020). Green Product Development under Competition: A Study of the Fashion Apparel Industry. European Journal of Operational Research, 280, 523-538. https://doi.org/10.1016/j.ejor.2019.07.050

He, R., Xiong, Y., \& Lin, Z. (2016). Carbon Emissions in a Dual Channel Closed Loop Supply Chain: The Impact of Consumer Free Riding Behavior. Journal of Cleaner Production, 134, 384-394. https://doi.org/10.1016/j.jclepro.2016.02.142

Hsiao, S. H., Wang, Y. Y., Wang, T. et al. (2019). How Social Media Shapes the Fashion Industry: The Spillover Effects between Private Labels and National Brands. Industrial Marketing Management, 86, 40-51. https://doi.org/10.1016/j.indmarman.2019.02.022

Kato, T. (2019). Influence of Showroom Visit Experience on Recommendation Intention in the Japanese Automotive Industry (pp. 1-5). 2019 International Conference on Engineering, Science, and Industrial Applications (ICESI). https://doi.org/10.1109/ICESI.2019.8862998

Kuksov, D., \& Liao, C. (2018). When Showrooming Increases Retailer Profit. Journal of Marketing Research, 55, 459-473. https://doi.org/10.1509/jmr.17.0059

Li, G., Li, L., \& Sun, J. (2019a). Pricing and Service Effort Strategy in a Dual-Channel Supply Chain with Showrooming Effect. Transportation Research Part E: Logistics and Transportation Review, 126, 32-48. https://doi.org/10.1016/j.tre.2019.03.019

Li, J., Yang, S., Shi, V. et al. (2019b). Partial Vertical Centralization in Competing Supply Chains. International Journal of Production Economics, 2019, Article ID: 107565. https://doi.org/10.1016/j.ijpe.2019.107565

Liu, L., Feng, L., Xu, B. et al. (2020). Operation Strategies for an Omni-Channel Supply Chain: Who Is Better Off Taking on the Online Channel and Offline Service? Electronic Commerce Research and Applications, 39, Article ID: 100918. https://doi.org/10.1016/j.elerap.2019.100918

McGuire, T. W., \& Staelin, R. (1983). An Industry Equilibrium Analysis of Downstream Vertical Integration. Marketing Science, 2, 161-191. https://doi.org/10.1287/mksc.2.2.161

Modak, N. M., \& Kelle, P. (2019). Managing a Dual-Channel Supply Chain under Price and Delivery-Time Dependent Stochastic Demand. European Journal of Operational Research, 272, 147-161. https://doi.org/10.1016/j.ejor.2018.05.067

Moon, I., Jeong, Y. J., \& Saha, S. (2018). Investment and Coordination Decisions in a Supply Chain of Fresh Agricultural Products. Operational Research, 1-25. https://doi.org/10.1007/s12351-018-0411-4

Pu, X., Gong, L., \& Han, X. (2017). Consumer Free Riding: Coordinating Sales Effort in a Dual-Channel Supply Chain. Electronic Commerce Research and Applications, 22, 1-12. https://doi.org/10.1016/j.elerap.2016.11.002

Qian, X., Chan, F. T. S., Zhang, J. et al. (2020). Channel Coordination of a Two-Echelon Sustainable Supply Chain with a Fair-Minded Retailer under Cap-and-Trade Regulation. Journal of Cleaner Production, 244, Article ID: 118715.

https://doi.org/10.1016/j.jclepro.2019.118715

Ranjan, A., \& Jha, J. K. (2019). Pricing and Coordination Strategies of a Dual-Channel 
Supply Chain Considering Green Quality and Sales Effort. Journal of Cleaner Production, 218, 409-424. https://doi.org/10.1016/j.jclepro.2019.01.297

Saha, S. (2013). Supply Chain Coordination through Rebate Induced Contracts. Transportation Research Part E: Logistics and Transportation Review, 50, 120-137. https://doi.org/10.1016/j.tre.2012.11.002

Schneider, P. J., \& Zielke, S. (2020). Searching Offline and Buying Online: An Analysis of Showrooming Forms and Segments. Journal of Retailing and Consumer Services, 52, Article ID: 101919. https://doi.org/10.1016/j.jretconser.2019.101919

Şen, A. (2008). The US Fashion Industry: A Supply Chain Review. International Journal of Production Economics, 114, 571-593. https://doi.org/10.1016/j.ijpe.2007.05.022

Taylor, T. A. (2002). Supply Chain Coordination under Channel Rebates with Sales Effort Effects. Management science, 48, 992-1007. https://doi.org/10.1287/mnsc.48.8.992.168

Tian, Y., Ma, J., Xie, L. et al. (2020). Coordination and Control of Multi-Channel Supply Chain Driven by Consumers' Channel Preference and Sales Effort. Chaos, Solitons \& Fractals, 132, Article ID: 109576. https://doi.org/10.1016/j.chaos.2019.109576

Tsay, A. A., \& Agrawal, N. (2000). Channel Dynamics under Price and Service Competition. Manufacturing \& Service Operations Management, 2, 372-391. https://doi.org/10.1287/msom.2.4.372.12342

Van Baal, S., \& Dach, C. (2005). Free Riding and Customer Retention across Retailers' Channels. Journal of Interactive Marketing, 19, 75-85.

https://doi.org/10.1002/dir.20036

Viejo-Fernández, N., Sanzo-Pérez, M. J., \& Vázquez-Casielles, R. (2020). Is Showrooming Really So Terrible? Start Understanding Showroomers. Journal of Retailing and Consumer Services, 54, Article ID: 102048.

https://doi.org/10.1016/j.jretconser.2020.102048

Wang, L., \& Song, Q. (2019). Pricing Policies for Dual-Channel Supply Chain with Green Investment and Sales Effort under Uncertain Demand. Mathematics and Computers in Simulation. https://doi.org/10.1016/j.matcom.2019.08.010

Xing, D., \& Liu, T. (2012). Sales Effort Free Riding and Coordination with Price Match and Channel Rebate. European Journal of Operational Research, 219, 264-271. https://doi.org/10.1016/j.ejor.2011.11.029

Yang, H., \& Chen, W. (2018). Retailer-Driven Carbon Emission Abatement with Consumer Environmental Awareness and Carbon Tax: Revenue-Sharing versus Cost-Sharing. Omega, 78, 179-191. https://doi.org/10.1016/j.omega.2017.06.012

Yang, L., \& Tang, R. (2019). Comparisons of Sales Modes for a Fresh Product Supply Chain with Freshness-Keeping Effort. Transportation Research Part E: Logistics and Transportation Review, 125, 425-448. https://doi.org/10.1016/j.tre.2019.03.020

Yang, L., Tang, R., \& Chen, K. (2017). Call, Put and Bidirectional Option Contracts in Agricultural Supply Chains with Sales Effort. Applied Mathematical Modelling, 47, 1-16. https://doi.org/10.1016/j.apm.2017.03.002

Zhang, J., Onal, S., \& Das, S. (2017). Price Differentiated Channel Switching in a Fixed Period Fast Fashion Supply Chain. International Journal of Production Economics, 193, 31-39. https://doi.org/10.1016/j.ijpe.2017.06.030

Zhang, Z., Liu, S., \& Niu, B. (2020). Coordination Mechanism of Dual-Channel Closed-Loop Supply Chains Considering Product Quality and Return. Journal of Cleaner Production, 248, Article ID: 119273. https://doi.org/10.1016/j.jclepro.2019.119273

Zhao, T., Xu, X., Chen, Y. et al. (2020). Coordination of a Fashion Supply Chain with Demand Disruptions. Transportation Research Part E: Logistics and Transportation 
Review, 134, Article ID: 101838. https://doi.org/10.1016/j.tre.2020.101838

Zhou, Y. W., Guo, J., \& Zhou, W. (2018). Pricing/Service Strategies for a Dual-Channel Supply Chain with Free Riding and Service-Cost Sharing. International Journal of Production Economics, 196, 198-210. https://doi.org/10.1016/j.ijpe.2017.11.014 